\title{
CORONARY ARTERY CALCIUM IS ASSOCIATED WITH LPA GENE VARIANT RS7765803-C IN MEXICAN MESTIZO POPULATION. THE GEA PROJECT
}

\author{
Guillermo C. Cardoso-Saldaña ${ }^{1 *}$, Rosalinda Posadas-Sánchez ${ }^{1}$, María del C. González-Salazar ${ }^{1}$, \\ José M. Fragoso-Lona², and Gilberto Vargas-Alarcón²
}

Departments of ${ }^{1}$ Endocrinology and ${ }^{2}$ Molecular Biology, Instituto Nacional de Cardiología Ignacio Chávez, SSA, Mexico City, Mexico

\begin{abstract}
Background: Lipoprotein(a) [Lp(a)] levels are genetically determined; high levels are a risk factor for coronary disease, although their association with coronary artery calcium (CAC) is controversial. Objective: The objective of the study was to assess the association of LPA gene polymorphisms with CAC in a Mexican Mestizo population. Methods: We included 1594 subjects 35-70 years old. Six polymorphisms of the LPA gene were analyzed. CAC score was determined by tomography and Lp(a) serum levels by immunonephelometry. The association of LPA polymorphism with CAC and Lp(a) was evaluated by logistic regression. Results: The prevalence of $L p(a) \geq 30 \mathrm{mg} / \mathrm{dL}$ was $10 \%$, and of CAC $>0$ was $26.9 \%$. Three polymorphisms were associated with high Lp(a) levels: rs10455872-G ( $p=0.013)$, rs6907156-T ( $p=0.021)$, and rs7765803-C ( $p=0.001)$. Homozygotes (CC) for the rs7765803 variant compared with the G allele (CG + GG) carriers had higher Lp(a) levels ( 8.9 [3.3-23.9] vs. 4.9 [2.3-11.2] $\mathrm{mg} / \mathrm{dL} ; \mathrm{p}=0.015)$ and higher prevalence of $\mathrm{CAC}>0(36.5 \% \mathrm{vs} .26 .3 \%, \mathrm{p}=0.045)$ and were associated with CAC > 0 (odds ratio $=1.7,95 \%$ confidence interval: $1.06-2.7 ; p<0.026$ ). The other polymorphisms were not associated with CAC. Conclusions: This is the first study to demonstrate in a Mexican Mestizo population that carriers of the rs7765803-C allele of LPA gene have 2.6 times greater risk for high $L p(a)$ values and 1.7 times higher risk for coronary artery disease. (REV INVEST CLIN. 2020;72(2):61-8)
\end{abstract}

Key words: LPA gene. Calcium score. Mexican Mestizo Population.

\section{INTRODUCTION}

Several retrospective, prospective, and meta-analyses studies have shown that a high serum level of lipoprotein(a) $[\operatorname{Lp}(a)]$ is an independent risk factor for atherosclerotic disease ${ }^{1-3}$. For more than 25 years,

*Corresponding author:

Guillermo C. Cardoso Saldaña

E-mail: gccardosos@yahoo.com the presence of $L p(a)$ has been described in atheroma and venous coronary grafts ${ }^{4-6}$. However, there are controversial data regarding the relationship between Lp(a) levels and coronary artery calcium (CAC) score: some authors found evidence of a positive relationship $^{7,8}$, while others reported no association ${ }^{9,10}$. The

Received for publication: 8-06-2019

Approved for publication: 17-09-2019

DOI: $10.24875 / R I C .19003138$

0034-8376 / (c) 2019 Revista de Investigación Clínica. Published by Permanyer. This is an open access article under the CC BY-NC-ND license (http://creativecommons.org/licenses/by-nc-nd/4.0/). 
usefulness of CAC as an atherosclerosis marker lies in that it can predict future cardiovascular events ${ }^{11-13}$. Some studies show significant heterogeneity in the relationship between $\mathrm{Lp}(\mathrm{a})$ levels and coronary heart disease (CHD), especially with regard to (1) gender and race, (2) prevalence of coronary risk factors between populations, and ( 3 ) the prevalence of LPA gene variant. It is thus possible that all these differences could explain the controversial data ${ }^{12,14-16}$.

In adult Mexican population, we have previously reported a prevalence of $14 \%$ for $\operatorname{Lp}(a) \geq 30 \mathrm{mg} / \mathrm{dL}$ and high $L p(a)$ levels associated with myocardial infarction in $33 \%$ of atherosclerotic subjects ${ }^{17}$. Moreover, subclinical atherosclerosis (evaluated by CAC score) was recently found in $27 \%$ of a Mexican Mestizo population without personal or familial history of coronary heart disease $(\mathrm{CHD})^{18}$. There is no information on the genetic variants of LPA in Mexican Mestizo population; however, some single-nucleotide polymorphisms (SNPs) in Mexican-American population $^{19}$ and in non-Hispanic Whites ${ }^{20}$, have been found associated with $L p(a)$ levels, although the association of LPA gene variants with coronary artery calcification (CAC) was not evaluated. Therefore, the purpose of this study was to investigate the role of LPA gene variants in both plasma $L p(a)$ levels and subclinical atherosclerosis (assessed by CAC score) in a genetically well-characterized Mexican Mestizo population.

\section{METHODS}

\section{Participants}

The study included 1594 Mexican Mestizos, who participated in the Genetics of Atherosclerotic Disease (Genética de la Enfermedad Ateroesclerosa [GEA]) Mexican study ${ }^{21}$. In summary, all GEA participants were Mexican Mestizos, 35-70 years of age, without a family history of premature CHD and free of clinically apparent cardiovascular disease. Subjects were recruited from donors at the blood bank of the $\mathrm{Na}$ tional Institute of Cardiology in Mexico City or by advertisements in social service centers. Participants were free of any acute illness and had normal performance status.

The study protocol was approved by the Institutional Ethics Committee and conducted according to the
Helsinki Declaration guidelines. All participants signed an informed consent letter.

\section{Demographic data and laboratory studies}

Validated questionnaires were applied to the participants to obtain demographic information, family and personal history of cardiovascular risk, physical activity, and use of medications. Weight was determined in kilograms $(\mathrm{kg})$ and height in meters using a calibrated scale and a wall stadiometer. Body mass index (BMI) was calculated with the formula weight/height ${ }^{2}$ $\left[\mathrm{kg} / \mathrm{m}^{2}\right]$. Waist was measured with a fiberglass metric tape at the midpoint of the distance between the lower part of the last rib and the iliac crest (with a 0.5 $\mathrm{cm}$ approximation). Systolic and diastolic arterial pressures were measured 3 times in the sitting position after at least 5 min rest; the average of the last two consecutive measurements was considered for the analysis.

Blood samples were obtained from an antecubital vein after a $10 \mathrm{~h}$ fasting period and $20 \mathrm{~min}$ in the sitting position. Glucose, total cholesterol, triglycerides, and high-density lipoprotein cholesterol (HDL-C) concentrations were determined in plasma by enzymatic methods (Roche/Hitachi, Germany) in a Hitachi 902 auto-analyzer (Hitachi LTD, Tokyo, Japan). Low-density lipoprotein cholesterol (LDL-C) was calculated with the Friedewald formula modified by DeLong et al. ${ }^{22}$; non-HDL-C was calculated subtracting the HDLC from total cholesterol. Reproducibility and accuracy of lipid and lipoprotein determinations were periodically evaluated by the Lipid Standardization Program of the Centers for Disease Control and Prevention (Atlanta, GA, USA). Intra- and inter-assay variation coefficients were below $3 \%$. Lp(a) concentrations were measured by kinetic immunonephelometry with the N Latex Lp(a) reagent (Siemens Healthcare Diagnostics Products $\mathrm{GmbH}$, Marburg, Germany) ${ }^{23}$ in automated BN ProSpec ${ }^{\oplus}$ equipment following manufacturer's instructions. Intra- and inter-assay variation coefficients were below $6 \%$.

\section{Tomographic measurements}

Computed tomography is a validated method for measuring visceral adipose tissue ${ }^{24}$. In the present study, coronary artery calcification (CAC) expressed 
in Hounsfield units (HU) was assessed using 64-detector helical tomography (Somatom Sensation, Siemens, Malvern, PA, USA) with cardiac synchronization by a prospective protocol with the following parameters: $120 \mathrm{kV}, 120 \mathrm{~mA}$, and $3 \mathrm{~mm}$ slices according to the Agatston method ${ }^{25}$, interpreted by experienced radiologists. Twenty different scans were randomly selected to evaluate the consistency of interpretation. Intraobserver coefficient correlation was 0.99 $(p<0.001)$.

\section{Determination of LPA genotypes}

DNA was extracted from peripheral blood according to the Lahiri and Nurnberger method ${ }^{26}$. $L p(a)$ is encoded by the LPA gene which is located on the chromosome 6q26-q27 region. Recent studies have associated six relevant SNPs in the LPA gene with increased $L p(a)$ levels, myocardial infarction, coronary artery disease (CAD), and major adverse cardiovascular events ${ }^{19,20}$ : one located in exon 15 C4192G Leu1358Val (rs7765803); four located in the introns $3,15,18$, and 38 (positions T132049C [rs6919346], A82290G [rs10455872], T76399C [rs6907156], and C8252T [rs1321195], respectively); and one upstream of the transcription site (position G12460658A [rs12212807]). The SNPs were genotyped using 5 'exonuclease TaqMan genotyping assays on an ABI Prism 7900HT Fast Real-Time PCR System, according to the manufacturer's instructions (Applied Biosystems, Foster City, USA). For each polymorphism, we identified the CAD-risk allele or the minor allele frequency; subjects carrying the risk allele were compared to those carrying the wild-type allele.

Because the Mexican Mestizo population is admixed, a panel of 265 ancestry informative markers distinguishing mainly Amerindian, European, and African ancestries was selected ${ }^{27}$ and genotyped on Illumina Bead Station using the GoldenGate assay. Duplicate control samples were genotyped on each chip, which served as internal controls for the quality of clustering and reproducibility. Genotyping accuracy was also assessed by genotype clustering using the Illumina gene train score, which is a measure of the clustering confidence of individual SNP alleles. Global ancestry (Caucasian, Amerindian, and African) was determined in all individuals using the ADMIXTURE software.

\section{Statistical analysis}

Data are expressed as mean and standard deviation or median and interquartile range for continuous variables, and as simple frequencies and percentages for categorical variables. Comparisons for continuous variables were performed with Student's t-test or Mann-Whitney U-test, according to the variable distribution. We used the Chi-square test for categorical variables. CAC was analyzed as a categorical variable (CAC >0 HU). Allelic and genotypic polymorphism frequencies were obtained through direct counting; the Hardy-Weinberg equilibrium (HWE) was assessed by a Chi-square test. To investigate the independence of the association of LPA gene polymorphisms with $\mathrm{Lp}(\mathrm{a}) \geq 30 \mathrm{mg} / \mathrm{dL}$ or the presence of CAC $>0 \mathrm{HU}$, multivariate logistic regression analysis adjusted by gender and age in model 2, plus BMl, triglycerides, LDL-C, diabetes mellitus, hypertension, and smoking in model 3 was used. $p<0.05$ was considered statistically significant. We used the statistics software SPSS V.16 to perform the analyses.

\section{RESULTS}

\section{Characteristics of the study sample}

Table 1 summarizes the general characteristics of the 1594 study subjects. The mean age of the population was $53.1 \pm 9.3$ years; $50.75 \%$ were women and $49.25 \%$ men. Of the six polymorphisms assessed in this study, rs10455872-G, rs6907156-T, and rs7765803-C alleles were associated with high median $L p(a)$ levels when compared with the major allele frequency (14.7 vs. $4.66 \mathrm{mg} / \mathrm{dL}, \mathrm{p}<0.001$; 22.4 vs. $5.04 \mathrm{mg} / \mathrm{dL}, \mathrm{p}<0.021$; and 8.6 vs. $4.8 \mathrm{mg} / \mathrm{dL}$, $\mathrm{p}<0.001$, respectively). In addition, the rs7765803-C variant was simultaneously associated with a high prevalence of subclinical atherosclerosis (CAC $>0 \mathrm{HU}$, $36.4 \%$ vs. $26.3 \%, p=0.022$ ).

The sample was then stratified according to rs7765803 LPA genotype into two groups: (1) CC genotype carriers (6.8\%) and (2) GC + GG genotype carriers $(93.2 \%)$ (Table 1 ). Subjects carrying the rs7765803-C allele had higher systolic and diastolic blood pressures $(p<0.01)$ and higher levels of $L p(a)$ $(8.6 \mathrm{mg} / \mathrm{dL}$ vs. $4.8 \mathrm{mg} / \mathrm{dL}, \mathrm{p}=0.001$ ). The prevalence 
Table 1. Characteristics of Mexican Mestizo participants according to rs7765803 genotype (CC and CG+GG) of LPA gene

\begin{tabular}{|c|c|c|c|}
\hline \multicolumn{4}{|c|}{ rs 7765803} \\
\hline & $\mathrm{CC}$ & $\mathrm{CG}+\mathrm{GG}$ & $p$ \\
\hline n (\%) & $108(6.8)$ & $1486(93.2)$ & \\
\hline Sex, F/M & $45 / 63$ & $764 / 722$ & \\
\hline Age, years & $53.3 \pm 9.4$ & $53.2 \pm 9.3$ & 0.95 \\
\hline Weight, kg & $76.3 \pm 15.0$ & $74.2 \pm 13.8$ & 0.13 \\
\hline BMI, kg/m² & $28.4 \pm 4.4$ & $28.4 \pm 4.4$ & 0.90 \\
\hline $\mathrm{SBP}, \mathrm{mmHg}$ & $121.6 \pm 21.9$ & $116.9 \pm 17.1$ & 0.007 \\
\hline $\mathrm{DBP}, \mathrm{mmHg}$ & $74.7 \pm 10.5$ & $72.0 \pm 9.3$ & 0.004 \\
\hline $\mathrm{TC}, \mathrm{mg} / \mathrm{dL}$ & $192.04 \pm 36.3$ & $192.9 \pm 37.5$ & 0.81 \\
\hline $\mathrm{TG}, \mathrm{mg} / \mathrm{dL}^{*}$ & $144.6(100.5-198.7)$ & $148.7(112.0-204.0)$ & 0.32 \\
\hline LDL-C, mg/dL & $118.4 \pm 31.5$ & $118.0 \pm 31.6$ & 0.88 \\
\hline $\mathrm{HDL}-\mathrm{C}, \mathrm{mg} / \mathrm{dL}$ & $46.4 \pm 13.4$ & $46.0 \pm 13.4$ & 0.76 \\
\hline Apo-B, mg/dL & $96.5 \pm 27.9$ & $96.5 \pm 28.0$ & 0.99 \\
\hline Apo-Al, mg/dL & $136.3 \pm 33.1$ & $138.0 \pm 36.1$ & 0.63 \\
\hline Glucose, mg/dL & $99.2 \pm 29.2$ & $99.0 \pm 33.6$ & 0.30 \\
\hline Insulin IU/mL* & $17.8(12.3-26.4)$ & $17.3(12.5-23.9)$ & 0.49 \\
\hline HOMA-IR* & $4.1(2.8-6.2)$ & $3.9(2.7-5.8)$ & 0.51 \\
\hline hsCRP mg/dL* & $1.73(0.7-7.8)$ & $1.5(0.8-3.2)$ & 0.96 \\
\hline $\operatorname{Lp}(a), \mathrm{mg} / \mathrm{dL}^{*}$ & $8.6(3.7-20.1)$ & $4.8(2.3-11.0)$ & 0.001 \\
\hline
\end{tabular}

Mean \pm SD, *median (interquartile range). BMI, body mass index; SBP, systolic blood pressure; DBP, diastolic blood pressure; TC, total cholesterol; TG, triglyceride; HDL-C and LDL-C, high- and low-density lipoprotein cholesterol; HOMA-IR, homeostatic model assessment of insulin resistance; hSCRP, high-sensitivity C-reactive protein; Lp(a), lipoprotein(a).

of $\mathrm{Lp}(\mathrm{a}) \geq 30 \mathrm{mg} / \mathrm{dL}$ and of $\mathrm{CAC}>0 \mathrm{HU}$ were significantly higher in rs7765803-C genotype carriers ( $9.4 \%$ vs. $20.5 \%, 20.5 \%$, and $36.4 \%$, respectively; Fig. 1 ).

Global ancestry proportions were estimated as $54 \%$ Native American, 35.8\% Caucasian, and 10\% African. Observed and expected frequencies were in HWE $(p>0.05)$. Age, BMI, and the concentration of lipids, $\mathrm{HDL}$ and LDL, apo-A, apo-B, and plasma glucose were similar to those observed in the rs7765803-G allele carriers ( $p=n s$ ) (Table 1 ). No significant differences were found in the prevalence of traditional risk factors, such as smoking habit, hypertension, and diabetes mellitus. A simple Spearman correlation analysis between clinical and metabolic variables with $L p(a)$ levels $\geq 30 \mathrm{mg} / \mathrm{dL}$ showed that only BMl in rs7765803-C allele carriers correlated negatively with $L p(a)$ levels $(p<0.001)$ (Table 2). In the GG + CG genotype carrier group, the systolic and diastolic blood pressure, glucose, insulin, and HOMA-IR correlated negatively $(p<0.001)$ with Lp(a) levels (Table 2 ).
The independence of the association between the rs7765803-C allele and the risk of $L p(a) \geq 30 \mathrm{mg} /$ $\mathrm{dL}$ or $\mathrm{CAC}>0 \mathrm{HU}$ was investigated by multivariate logistic regression analysis (Fig. 2). The rs7765803-C allele carriers had a higher risk of $\mathrm{Lp}(\mathrm{a}) \geq 30 \mathrm{mg} / \mathrm{dL}$ : (a) odds ratio $(O R)=2.4$ (95\% confidence interval $(\mathrm{Cl})=1.07-5.6, \mathrm{p}<0.034)$ under an unadjusted mod$\mathrm{el}$; (b) OR $=2.5(95 \% \mathrm{Cl}=1.09-5.8, \mathrm{p}=0.030)$ under model 2 adjusted for gender and age; and (c) $\mathrm{OR}=2.7$ $(95 \% \mathrm{Cl}=1.1-6.3, \mathrm{p}=0.02)$ under model 3 after complete adjustment. Allele rs7765803-C was also associated with a risk of presenting $\mathrm{CAC}>0 \mathrm{HU}$ : (a) unadjusted model, $\mathrm{OR}=1.6(95 \% \mathrm{Cl}=1.06-2.4$, $\mathrm{p}<0.023$ ); (b) gender and age-adjusted model, OR $=1.6(95 \% \mathrm{Cl}=1.01-2.5, \mathrm{p}<0.045)$; and (c) OR $=1.6(95 \% \mathrm{Cl}=1.01-2.6, \mathrm{p}=0.047)$ after adjusting for several traditional coronary risk factors. In both cases, the rs7765803-C allele was significantly associated with increased risk of developing CAC $>0$ $\mathrm{HU}$, as well as with higher Lp(a) levels in our population (Fig. 2). 
Figure 1. Lipoprotein(a) $\geq 30 \mathrm{mg} / \mathrm{dL}$ and CAC $>0 \mathrm{HU}$ prevalence in Mexican Mestizo population according to rs7765803 genotype. ${ }^{*} p=0.029,{ }^{* *} p=0.022$. CC versus $C G+G G$. Chi-square test.

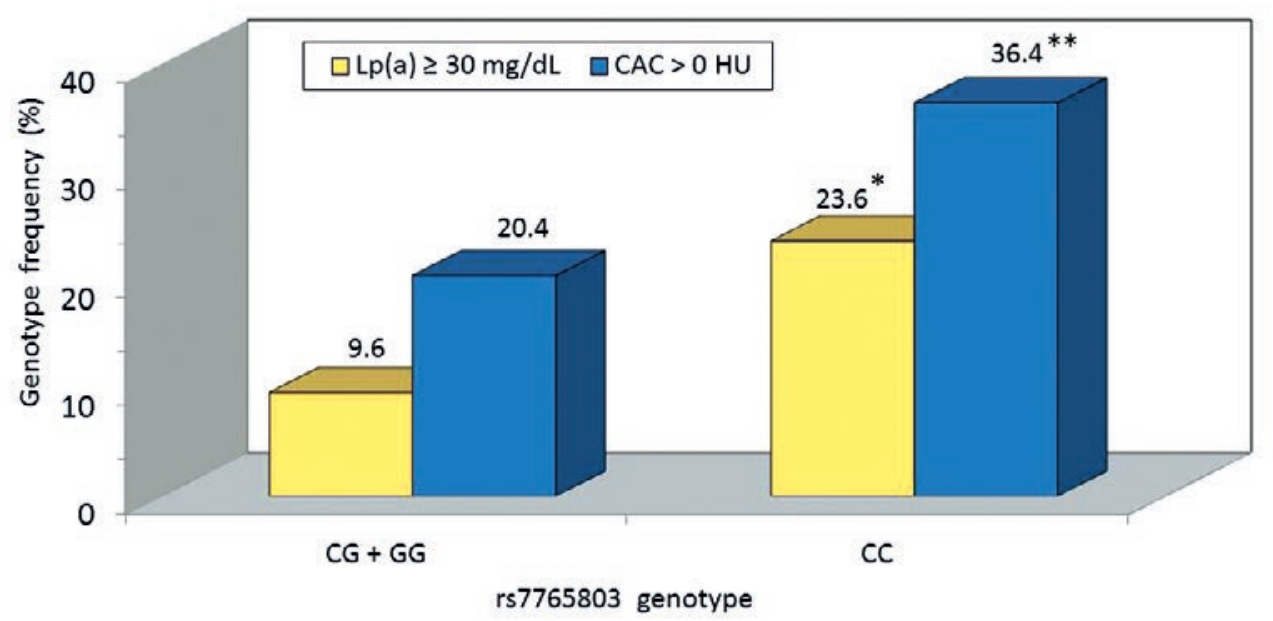

Figure 2. Association of rs7765803-C allele with high lipoprotein(a) levels or coronary artery calcification in a Mexican Mestizo population. Model 1: not adjusted. Model 2: adjusted by gender and age. Model 3: adjusted by Model 2 plus body mass index, triglycerides, low-density lipoprotein cholesterol, diabetes mellitus, hypertension, and smoking.

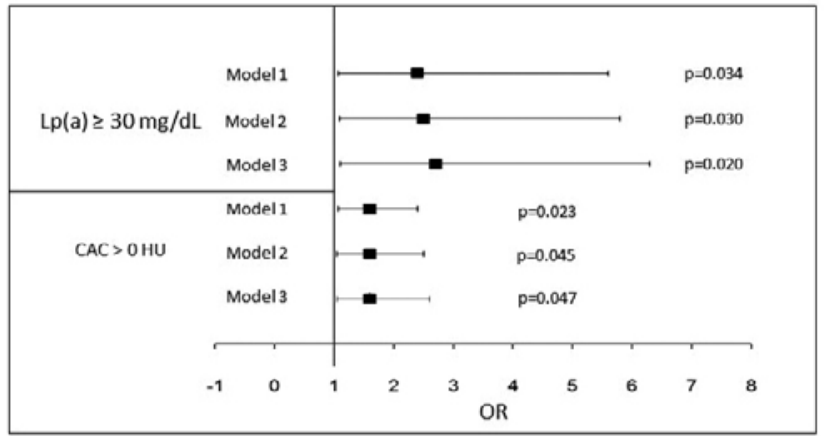

\section{DISCUSSION}

Lp(a) serum levels have long been recognized as an independent risk factor for $C A D^{1-3}$. However, $\operatorname{Lp}(a)$ concentrations and their relationship with cardiovascular disease vary across races/ethnicities. The distinctive feature of $L p(a)$ is the presence of $A p o(a)$, a glycoprotein similar to plasminogen. Apo(a) contains a single copy of plasminogen-like kringle $\mathrm{V}$ and multiple copies of kringle IV (KIV) type 2 that have been classified into 10 different types based on their sequence homology ${ }^{28}$. The LPA gene is a major determinant of the KIV type 2 repetitions in Apo(a) and accounts for more than $90 \%$ of $L p(a)$ concentration in plasma ${ }^{29}$. However, $\mathrm{Lp}(\mathrm{a})$ concentrations and their relationship with cardiovascular disease vary across races/ethnicities ${ }^{30}$.

This is the first study conducted in a large genetically well-characterized Mexican Mestizo population without CHD, with the purpose of investigating the relationship between CAC and $L p(a)$ depending on LPA gene polymorphisms. The main findings were that (a) $6.8 \%$ of the subjects were genotyped as homozygous for the CC allele of the rs7765803 LPA polymorphism; (b) the levels of $L p(a)$ were $\geq 30 \mathrm{mg} / \mathrm{dL}$ in $20.5 \%$ of the subjects; and (c) $36.4 \%$ had subclinical atherosclerosis defined by CAC score $>0 \mathrm{HU}$. Both percentages ( $50 \%$ and $10 \%$ ) were significantly higher than those observed in rs7765803-G allele carriers 
Table 2. Spearman correlation of clinical and metabolic variables with plasma lipoprotein(a) levels categorized by rs7765803 genotype

\begin{tabular}{lcc}
\hline & \multicolumn{2}{c}{ rs7765803 } \\
\hline $\mathrm{n}$ & 108 & $\mathrm{CG}+\mathrm{GG}$ \\
$\mathrm{Age}$, years & -0.09 & 1486 \\
$\mathrm{BMI}$ & $-0.33^{* *}$ & -0.04 \\
$\mathrm{SBP}, \mathrm{mmHg}$ & -0.42 & -0.06 \\
$\mathrm{DBP}, \mathrm{mmHg}$ & -0.13 & $-0.137^{* *}$ \\
$\mathrm{TC}, \mathrm{mg} / \mathrm{dL}$ & -0.043 & $-0.114^{* *}$ \\
$\mathrm{TG}, \mathrm{mg} / \mathrm{dL}$ & 0.17 & 0.15 \\
$\mathrm{HDL}-\mathrm{C}, \mathrm{mg} / \mathrm{dL}$ & 0.04 & $-0.080^{*}$ \\
$\mathrm{LDL}-\mathrm{C}, \mathrm{mg} / \mathrm{dL}$ & -0.12 & $0.065^{*}$ \\
Glucose, mg/dL & -0.068 & $0.07^{*}$ \\
Insulin, UI/mL & -0.10 & $-0.114^{* *}$ \\
$\mathrm{HOMA}-\mathrm{IR}$ & -0.12 & $-0.124^{* *}$ \\
$\mathrm{hsCRP}, \mathrm{mg} / \mathrm{dL}$ & -0.15 & $-0.139^{* *}$ \\
\hline
\end{tabular}

${ }^{*} p<0.05,{ }^{* *} p<0.001$. BMI, body mass index; SBP, systolic blood pressure; DBP, diastolic blood pressure; TC, total cholesterol; TG, triglyceride; HDL-C and LDL-C, high- and low-density lipoprotein cholesterol; HOMA-IR, homeostatic model assessment of insulin resistance; hsCRP, high-sensitivity C-reactive proteincholesterol; TG, triglyceride; HDL-C and LDL-C, highand low-density lipoprotein cholesterol; HOMA-IR, homeostatic model assessment of insulin resistance; hsCRP, high-sensitivity C-reactive protein; $L p(a)$, lipoprotein(a).

$(p<0.02)$. Compared with subjects with the rs7765803-G variant, homozygous rs7765803-C allele carriers had 2.7 times greater risk of $L p(a)$ levels $\geq 30 \mathrm{mg} / \mathrm{dL}$ and 1.6 times greater risk of CAC $>0 \mathrm{HU}$; this comparison is independent of traditional risk factors (sex, BMI, blood pressure, lipids, lipoproteins, and HOMA-IR) for CHD.

Lp(a) has been found in atheroma plaques for more than 25 years and has already been identified as a predictor for major cardiovascular events ${ }^{5}$. Despite this evidence, the relationship between $\mathrm{Lp}(\mathrm{a})$ and subclinical atherosclerosis is still controversial. A positive relationship has been observed in some studies ${ }^{6,20,28,29}$, while no association has been reported in others ${ }^{10,12,31}$. These inconsistencies may in part be due to (1) small sample sizes; (2) inclusion of patients with diabetes ${ }^{15}$, hypertension ${ }^{32}$, or dyslipidemia ${ }^{4,33}$ in clinical studies; (3) studies with exclusively Caucasian, Afro-American, or multiethnic subjects despite the well-known fact that $L p(a)$ levels are clearly different between racial groups ${ }^{34}$ and widely diverse across ethnic groups; and (4) mediated by LPA gene polymorphism distribution ${ }^{35}$. Some studies have shown that LPA SNPs could be associated with elevated $L p(a)$ levels in certain populations and with low levels in others ${ }^{20}$. Differences in both $L p(a)$ levels between ethnic groups and the distribution of LPA gene polymorphisms could explain the inconsistencies indicated above. In addition, these differences prompted us to investigate in a Mexican Mestizo population, the relationship of LPA gene polymorphism with plasma $L p(a)$ levels and with subclinical atherosclerosis evaluated by CAC score.

In this study, three out of six LPA SNPs were significantly associated with elevated $\operatorname{Lp}(\mathrm{a})$ levels (rs10455872-G, rs6907156-T, and rs7765803-C). Of note, only one allele (rs7765803-C) was additionally associated with increased $L p(a)$ levels and the presence of CAC. These results are consistent with the previous reports that included 20 SNPs for LPA in a cohort of 3145 Europeans and 1749 MexicanAmericans; the rs7765803 SNP was found significantly associated with high $L p(a)$ levels, $p<1 \times 10^{-6}$ and $p<8.54 \times 10^{-5}$, respectively ${ }^{19,20}$.

The rs10455872-G allele of LPA has a prevalence of $7 \%{ }^{36}-15 \%{ }^{19}$ in the European population and has been associated with high Lp(a) levels, CHD, and aortic valve stenosis. In contrast, in a previous study, we found in a Mexican Mestizo population that this LPA allele was associated with higher levels of $L p(a)$ but not with subclinical atherosclerosis ${ }^{37}$. Our results are consistent with the previous reports in Latin American and East Asian populations. In those studies, a significant association with myocardial infarction was found, suggesting a causal relationship ${ }^{20}$. Interestingly, in this Mexican Mestizo population, we found an association of rs10455872-G and rs6907156-T alleles with high $\operatorname{Lp}(\mathrm{a})$ levels, which had already been reported for Mexican-American subjects ${ }^{19}$. However, these two alleles present in a Mexican Mestizo population without a history of CHD were not associated to the presence of subclinical atherosclerosis. These results underscore the importance of familial history of $\mathrm{CHD}$, which frequently is not taken into account in study designs.

This study has several strengths. First, this is a large genetically well-characterized Mexican Mestizo 
population without a personal or familial history of $\mathrm{CHD}$. Second, to the best of our knowledge, this is the first study to include, in a Mexican Mestizo population, Lp(a) levels, CAC score, and LPA SNPs, simultaneously. Third, our study provides evidence for an association between the LPA variants and CAC independently of clinical, biochemical, or metabolic coronary risk factors. Of note, these relationships have not been reported before in this population. Finally, assessment of CAC score has many potential clinical applications: supplementing prognostic information for CHD, identifying subjects who may benefit from a more aggressive treatment and/or further diagnostic workup, and evaluating the efficacy of risk factor modification or medical treatments on plaque burden $^{38}$.

Being a cross-sectional study, one cannot establish a causal relationship but can only make inferences. Since studies reporting associations with SNPs need replication in an independent sample before stating significant associations, and considering that this is the first report of an association of the rs7765803 polymorphisms with CAC, our results should be replicated in other Mexican Mestizo samples. Another limitation of the present work is that since the sample consisted of volunteers, participants may not have represented the general population. Nevertheless, the prevalence of CHD risk factors observed in this study is similar to that found in the ENSANUT, a survey with national representation ${ }^{39}$.

Our study, performed in a genetically well-characterized Mexican Mestizo population, demonstrated that rs7765803-C allele of LPA is significantly and independently associated with $L p(a)$ concentrations $\geq 30$ $\mathrm{mg} / \mathrm{dL}$ as well as with the presence of subclinical atherosclerosis, CAC >0 HU. The Lp(a) prevalence of $\geq$ $30 \mathrm{mg} / \mathrm{dL}$ was $10 \%$, and the presence of CAC was $26.9 \%$. Compared to subjects carrying the $G$ allele, the subjects homozygous for the rs7765803-C allele of the LPA gene had a 2.6 -fold greater risk of high $L p(a)$ serum levels and a 1.7 times higher risk of subclinical atherosclerosis. Our results highlight the importance of replicating these results in another sample of the Mestizo population without premature atherosclerosis to advance the understanding of the genetic basis of subclinical atherosclerosis. Hence, longitudinal studies would be useful to demonstrate a causal relationship of rs7765803-C allele of LPA as a genetic marker of subclinical atherosclerosis in the Mexican population.

\section{ACKNOWLEDGEMENTS}

This study was partly supported by a grant from the Consejo Nacional de Ciencia y Tecnología (CONACyT 2016-01-1958). The authors are grateful to the study participants and the clinical staff of the Genetics of the Atherosclerotic Disease (GEA) project.

\section{REFERENCES}

1. Nordestgaard BG, Chapman MJ, Ray K, Borén J, Andreotti F, Watts GF, et al. European atherosclerosis society consensus panel. Lipoprotein(a) as a cardiovascular risk factor: current status. Eur Heart J. 2010;31:2844-53.

2. Dubé JB, Boffa MB, Hegele RA, Koschinsky ML. Lipoprotein(a): more interesting than ever after 50 years. Curr Opin Lipidol. 2012;23:133-40.

3. Danesh J, Collins R, Peto R. Lipoprotein(a) and coronary heart disease. Meta-analysis of prospective studies. Circulation. 2000; 102:1082-5.

4. Cambillau M, Simon A, Amar J, Giral P, Atger V, Segond P, et al. Serum $L p(a)$ as a discriminant marker of early atherosclerotic plaque at three extracoronary sites in hypercholesterolemic men. The PCVMETRA Group. Arterioscler Thromb. 1992;12: 1346-52.

5. Rath M, Niendorf A, Reblin T, Dietel M, Krebber HJ, Beisiegel $U$. Detection and quantification of lipoprotein(a) in the arterial wall of 107 coronary bypass patients. Arteriosclerosis. 1989;9:579-92.

6. Cushing GL, Gaubatz JW, Nava ML, Burdick BJ, Bocan TM, Guyton JR, et al. Quantitation and localization of apolipoproteins [a] and $B$ in coronary artery bypass vein grafts resected at re-operation. Arteriosclerosis. 1989;9:593-603.

7. Superko HR, Hecht HS. Metabolic disorders contribute to subclinical coronary atherosclerosis in patients with coronary calcification. Am J Cardiol. 2001;88:260-4.

8. Verweij SL, de Ronde MW, Verbeek R, Boekholdt SM, Planken RN, Stroes ES, et al. Elevated lipoprotein(a) levels are associated with coronary artery calcium scores in asymptomatic individuals with a family history of premature atherosclerotic cardiovascular disease. J Clin Lipidol. 2018;12:597-6030.

9. Mahoney LT, Burns TL, Stanford W, Thompson BH, Witt JD, Rost $\mathrm{CA}$, et al. Coronary risk factors measured in childhood and young adult life are associated with coronary artery calcification in young adults: the Muscatine study. J Am Coll Cardiol. 1996; 27:277-84.

10. Nishino M, Malloy MJ, Naya-Vigne J, Russell J, Kane JP, Redberg RF. Lack of association of lipoprotein(a) levels with coronary calcium deposits in asymptomatic postmenopausal women. ] Am Coll Cardiol. 2000;35:314-20.

11. Cassidy AE, Bielak LF, Kullo IJ, Klee GG, Turner ST, Sheedy PF $2^{\text {nd }}$, et al. Sex-specific associations of lipoprotein(a) with presence and quantity of coronary artery calcification in an asymptomatic population. Med Sci Monit. 2004;10:CR493-503.

12. Guerra R, Yu Z, Marcovina S, Peshock R, Cohen JC, Hobbs HH. Lipoprotein(a) and apolipoprotein(a) isoforms: no association with coronary artery calcification in the Dallas heart study. Circulation. 2005;111:1471-9.

13. Lee TC, O'Malley PG, Feuerstein I, Taylor AJ. The prevalence and severity of coronary artery calcification on coronary artery computed tomography in black and white subjects. J Am Coll Cardiol. 2003;41:39-44

14. Sharrett AR, Ballantyne CM, Coady SA, Heiss G, Sorlie PD, Catellier D, et al. Coronary heart disease prediction from lipoprotein cholesterol levels, triglycerides, lipoprotein(a), apolipoproteins 
$A-I$ and $B$, and $H D L$ density subfractions: the atherosclerosis risk in communities (ARIC) study. Circulation. 2001;104:1108-13.

15. Qasim AN, Martin SS, Mehta NN, Wolfe ML, Park J, Schwartz S, et al. Lipoprotein(a) is strongly associated with coronary artery calcification in Type-2 diabetic women. Int J Cardiol. 2011; 150:17-21.

16. Shai I, Schulze MB, Manson JE, Stampfer MJ, Rifai N, Hu FB, A prospective study of lipoprotein(a) and risk of coronary heart disease among women with Type 2 diabetes. Diabetologia. 2005;48:1469-76

17. Cardoso-Saldaña G, Ize-Lema I, Kimura LY, Zamora González J, Posadas Romero C. Lipoprotein(a) and cardiovascular risk in adult Mexicans. Rev Invest Clin. 1997;49:85-92.

18. Posadas-Romero C, López-Bautista F, Rodas-Díaz MA, PosadasSánchez R, Kimura-Hayama E, Juárez-Rojas JG, et al. Prevalence and extent of coronary artery calcification in an asymptomatic cardiovascular Mexican population: genetics of atherosclerotic disease study. Arch Cardiol Mex. 2017;87:292-301.

19. Dumitrescu L, Glenn K, Brown-Gentry K, Shephard C, Wong M, Rieder MJ, et al. Variation in LPA is associated with Lp(a) levels in three populations from the third national health and nutrition examination survey. PLoS One. 2011;6:e16604.

20. Lee SR, Prasad A, Choi YS, Xing C, Clopton P, Witztum JL, et al. LPA gene, ethnicity, and cardiovascular events. Circulation. 2017; 135:251-63.

21. Villarreal-Molina T, Posadas-Romero C, Romero-Hidalgo S, Antúnez-Argüelles E, Bautista-Grande A, Vargas-Alarcón G, et al. The ABCA1 gene R230C variant is associated with decreased risk of premature coronary artery disease: the genetics of atherosclerotic disease (GEA) study. PLoS One. 2012;7:e49285.

22. DeLong DM, DeLong ER, Wood PD, Lippel K, Rifkind BM. A comparison of methods for the estimation of plasma low-and very low-density lipoprotein cholesterol. The lipid research clinics prevalence study. JAMA. 1986;256:2372-7.

23. Marcovina SM, Albers J], Scanu AM, Kennedy H, Giaculli F, Berg $\mathrm{K}$, et al. Use of a reference material proposed by the international federation of clinical chemistry and laboratory medicine to evaluate analytical methods for the determination of plasma lipoprotein(a). Clin Chem. 2000;46:1956-67.

24. Maurovich-Horvat P, Massaro J, Fox CS, Moselewski F, O’Donnell C J, Hoffmann U. Comparison of anthropometric, area and volume-based assessment of abdominal subcutaneous and visceral adipose tissue volumes using multi-detector computed tomography. Int J Obes (Lond). 2007;31:500-6.

25. Mautner GC, Mautner SL, Froehlich J, Feuerstein IM, Proschan MA, Roberts WC, et al. Coronary artery calcification: assessment with electron beam CT and histomorphometric correlation. Radiology. 1994;192:619-23.

26. Lahiri DK, Nurnberger Jl Jr. A rapid non-enzymatic method for the preparation of HMW DNA from blood for RFLP studies. Nucleic Acids Res. 1991;19:5444
27. Silva-Zolezzi I, Hidalgo-Miranda A Estrada-Gil ], Fernandez-Lopez JC, Uribe-Figueroa L, Contreras A, et al. Analysis of genomic diversity in Mexican Mestizo populations to develop genomic medicine in Mexico. Proc Natl Acad Sci U S A. 2009; 106:8611-6

28. Marcovina SM, Zhang ZH, Gaur VP, Albers Jj. Identification of 34 apolipoprotein(a) isoforms: differential expression of apolipoprotein(a) alleles between American blacks and whites. Biochem Biophys Res Commun. 1993;191:1192-6.

29. Boerwinkle E. Genetics of plasma lipoprotein(a) concentrations. Curr Opin Lipidol. 1992;3:128-36.

30. Gaubatz JW, Ghanem KI, Guevara J Jr., Nava ML, Patsch W, Morrisett JD. Polymorphic forms of human apolipoprotein[a]: inheritance and relationship of their molecular weights to plasma levels of lipoprotein[a]. J Lipid Res. 1990;31:603-13.

31. Taylor AJ, Feuerstein I, Wong H, Barko W, Brazaitis M, O'Malley PG. Do conventional risk factors predict subclinical coronary artery disease? Results from the prospective army coronary calcium project. Am Heart J. 2001;141:463-8.

32. Ghorbani A, Rafieian-Kopaei M, Nasri H. Lipoprotein (a): more than a bystander in the etiology of hypertension? A study on essential hypertensive patients not yet on treatment. J Nephropathol. 2013;2:67-70

33. Konerman M, Kulkarni K, Toth PP, Jones SR. Evidence of dependence of lipoprotein(a) on triglyceride and high-density lipoprotein metabolism. J Clin Lipidol. 2012;6:27-32.

34. Scholz M, Kraft HG, Lingenhel A, Delport R, Vorster EH, Bickeböller $\mathrm{H}$, et al. Genetic control of lipoprotein(a) concentrations is different in Africans and Caucasians. Eur J Hum Genet. 1999 7:169-78

35. Enkhmaa B, Anuurad E, Berglund L. Lipoprotein (a): impact by ethnicity and environmental and medical conditions. J Lipid Res. 2016;57:1111-25.

36. Clarke R, Peden JF, Hopewell JC, Kyriakou T, Goel A, Heath SC, et al. Genetic variants associated with $\operatorname{Lp}(a)$ lipoprotein level and coronary disease. N Engl J Med. 2009;361:2518-28.

37. Cardoso-Saldaña G, Fragoso J M, Lale-Farjat S, Torres-Tamayo M, Posadas-Romero C, Vargas-Alarcón G and Posadas-Sánchez $\mathrm{R}$. The rs10455872-G allele of the LPA gene is associated with high lipoprotein(a) levels and increased aortic valve calcium in a Mexican adult population. Genetics and Molecular Biology. 2019:42:519-25.

38. Cardarelli R, Hall A, Rankin W. Coronary artery calcium progression is associated with cardiovascular events among asymptomatic individuals: from the North Texas primary care practicebased research network (NorTex-PBRN). J Am Board Fam Med. 2017;30:592-600

39. Hernández-Avila M, Romieu I, Parra S, Hernández-Avila J, Madrigal $\mathrm{H}$, Willett $\mathrm{W}$. Validity and reproducibility of a food frequency questionnaire to assess dietary intake of women living in Mexico city. Salud Publica Mex. 1998;40:133-40. 